\title{
A study of Docetaxel-induced effects in MCF-7 cells by means of Raman microspectroscopy
}

\author{
Katharina Hartmann • Melanie Becker-Putsche • \\ Thomas Bocklitz • Katharina Pachmann • \\ Axel Niendorf • Petra Rösch • Jürgen Popp
}

Received: 9 December 2011 /Revised: 15 February 2012 / Accepted: 17 February 2012 /Published online: 8 March 2012

(C) The Author(s) 2012. This article is published with open access at Springerlink.com

\begin{abstract}
Chemotherapies feature a low success rate of about $25 \%$, and therefore, the choice of the most effective cytostatic drug for the individual patient and monitoring the efficiency of an ongoing chemotherapy are important steps towards personalized therapy. Thereby, an objective method able to differentiate between treated and untreated cancer cells would be essential. In this study, we provide molecular insights into Docetaxel-induced effects in MCF-7 cells, as a model system for adenocarcinoma, by means of Raman
\end{abstract}

This document is a collaborative effort of Melanie Becker-Putsche and Katharina Hartmann and they contributed equally to the presented work.

Electronic supplementary material The online version of this article (doi:10.1007/s00216-012-5887-9) contains supplementary material, which is available to authorized users.

K. Hartmann · M. Becker-Putsche · T. Bocklitz $\cdot$ P. Rösch $\cdot$ J. Popp $(\bowtie)$

Institute of Physical Chemistry and Abbe Center of Photonics, University of Jena,

Helmholtzweg 4,

07743 Jena, Germany

e-mail: juergen.popp@uni-jena.de

K. Hartmann · M. Becker-Putsche $\cdot$ T. Bocklitz $\cdot$ J. Popp

Institute of Photonic Technology,

Albert-Einstein-Straße 9,

07745 Jena, Germany

K. Pachmann

Department of Hematology and Oncology,

Clinic for Internal Medicine II, University Hospital Jena,

07740 Jena, Germany

\section{A. Niendorf}

Pathologie Hamburg-West,

Institut für diagnostische Histopathologie und Zytologie,

Lornsenstraße 4,

22767 Hamburg, Germany microspectroscopy combined with powerful chemometric methods. The analysis of the Raman data is divided into two steps. In the first part, the morphology of cell organelles, e.g. the cell nucleus has been visualized by analysing the Raman spectra with $k$-means cluster analysis and artificial neural networks and compared to the histopathologic gold standard method hematoxylin and eosin staining. This comparison showed that Raman microscopy is capable of displaying the cell morphology; however, this is in contrast to hematoxylin and eosin staining label free and can therefore be applied potentially in vivo. Because Docetaxel is a drug acting within the cell nucleus, Raman spectra originating from the cell nucleus region were further investigated in a next step. Thereby we were able to differentiate treated from untreated MCF-7 cells and to quantify the cell-drug response by utilizing linear discriminant analysis models.

Keywords Raman microspectroscopy - Docetaxel - Breast cancer $\cdot$ MCF-7

\section{Introduction}

Breast cancer is the most common cause of death of women worldwide [1]. Due to the low effectiveness of chemotherapeutic agents of about $25 \%$ as one possible origin of the high mortality rates [2], it is of utmost importance to achieve a comprehensive understanding about the therapeutic mechanism of cytostatics in order to improve chemotherapy. In addition, monitoring the efficiency of an ongoing chemotherapy and supporting the choice of the most effective cytostatic drug would be an important step towards personalized therapy. 
In the current clinical practice, the choice of chemotherapeutic drugs for patients is based on clinical trials and observations made on the courses of a disease for other patients. This practice harbours the risk that the individuality of patients is disregarded. Also the selection of drug combinations is widely empirical and often done by trial and error. However, since the introduction of chemotherapeutic agents investigations deal with an optimization of the drug selection for the individual patient. Especially in vitro chemosensitivity tests to predict a chemotherapy response gain impact, e.g. 3-(4,5-dimethyl-thiazol-2-yl)-2,5diphenyl-tetrazolium bromide (MTT), membrane and ATP assays and genomic analyses [3-5]. Nevertheless, some assays turned out to be insufficient of directing therapy [5] and the above mentioned techniques are not widely used in clinical practice.

During the last decades Docetaxel (DCT, Taxotere ${ }^{\circledR}$ ) became a widely used chemotherapeutic agent [6] against prostate, lung, stomach and ovarian cancer. It is known as highly active anticancer drug and one of the most effective medication against breast carcinoma [7]. DCT is a semisynthetic taxane, which is produced by the esterification of 10-deacetyl baccatin III, an extract from needles of the European yew (Taxus baccata L.) [8].

DCT has an enoumerous affinity to the $\beta$-tubulin of the microtubules of the cytoskeleton. Commonly there is an equilibrium between polymerisation and depolymerisation of the microtubles. This dynamic reorganisation is import for several cellular processes, e.g. the uptake, transport and secretion of vesicles, cell movements, formation of the cell shape and segregation of the chromosomes during mitosis [9]. A DCT treatment disturbs the depolymerisation of the microtubles causing a cell-cycle arrest [9-11]. Thereby, an ongoing controversy about the exact mode of action and the death mechanism exists: Morse et al. determined the nonapoptotic mitotic catastrophe with its missegregation of the chromosomes during mitosis and resulting micronuclei as the primary death mechanism of DCT treated human breast cancer cells, e.g. MCF-7 [9]. In contrast several other contributions report about apoptosis as the main mechanism of cell death after a DCT treatment induced mitotic catastrophe [12-15]. In this controversy, it should be also considered, that the response of antimicrotuble drugs might cause a dose- and cell line-specific mixtures between apoptotic and mitotic cell death, depending on the genetic background [9, $10,16]$.

Raman spectroscopy in combination with optical microscopy has established itself because of its non-invasive character, high molecular specificity, minimal sample preparation and high spatial resolution in the micrometer range to an extremely powerful analytical method. Thereby Raman microscopy has been recognized within the last years to be a very capable method to analyse biological samples like, e.g. eukaryotes [17-21] as well as prokaryotes [22-28] and even viruses [29]. By doing so, it allows answering a broad range of biomedical questions like, e.g. early diagnosis of cancer [30-36]. Because of the subtle biological differences involved, this requires a multivariate treatment of Raman spectra in order to extract all necessary bio-chemical information [37].

In comparison to Fourier transform infrared spectroscopy, which is also capable to acquire structural information of cell organelles [38], Raman microspectroscopy provides the unique capability to observe biochemical information from living cells [39-41]. Thereby, the non-disturbing low Raman-scattering cross section of water is of crucial importance. It allows the investigation of living cells in buffer solution or in their culture media.

Furthermore, several publications deal with the effects of chemotherapeutic agents on cells: In 1982, Manfait et al. already investigated the interaction of the anthracycline Adriamycin with human DNA via Raman and resonance Raman spectroscopy and found that the chromophores of Adriamycin intercalate into the GC sequences of the DNA and that hydrogen bonds are formed [42]. In recent years, many experiments cover the biochemical and spectral changes in Raman spectra of cells undergoing apoptosis due to a treatment with chemotherapeutic drugs. Especially the investigation of living cells gains impact [39-41]. Thereby, Raman spectra from the same living cells at different intervals were detected. Zoladek et al. even presented an experimental setup, which allows the maintenance of the cells under sterile physiological conditions during Raman measurements [40]. Currently, the optimization of the experimental design is of interest. Laser tweezers were applied to both optical trapping of single suspensions cells and simultaneous Raman spectroscopy [43] as well as singlecell patterned microarrays [39]. In addition, modern techniques like resonance Raman and surface enhanced resonance Raman scattering [44] and surface enhanced Raman scattering (SERS) [45] were utilized to monitor the effects introduced by chemotherapeutic agents on cancer cells. Hence, SERS has shown its potential as a simple and sensitive drug screening tool potentially even in vivo.

The aim of the current study is to investigate the interaction between DCT and the cultivated human breast adenocarcinoma cell line MCF-7 by Raman microspectroscopy in combination with special statistical/chemometrical methods. The resulting Raman images will be validated by the histopathological gold standard hematoxylin and eosin staining. Furthermore the additionally information in the Raman scans should be used for determining the function of DCT on MCF-7 cells in a quantitative and objective manner. The successful realization of these goals would be a significant step towards a personalized medicine applying Raman microspectroscopy as control tool. 


\section{Materials and methods}

Cell line selection and cell cultivation

The breast cancer cell line MCF-7 (Michigan Cancer Foundation-7), established by Soule et al. in 1973, contains isolated epithelial cells from a pleural effusion from a 69 years old caucasian female patient with metastatic mammary carcinoma [46]. Cells were cultivated in cell culture flasks with Roswell Park Memorial Institute 1640 medium supplemented with $10 \%$ fetal bovine serum and $1 \%$ penicillin/streptomycin. Cultures were maintained at $37{ }^{\circ} \mathrm{C}$ in a humified atmosphere of $5 \% \mathrm{CO}_{2}$. For the experiments, cells were harvested by trypsinization, centrifugation and finally re-cultured on fused silica slides (Frank Optic Products GmbH, Germany) in petri dishes with the same cultivation conditions for further $24 \mathrm{~h}$.

\section{Cell treatment with DCT}

DCT powder was resolved in ethanol and diluted by the growth media. Thereby, the used DCT solution contains an ethanol content of only $0.1 \%$ to prevent chemical alterations in $\mathrm{MCF}-7$ cells.

MCF-7 cells were exposed to the growth medium supplemented with various DCT concentrations. Table 1 gives an overview of the applied concentrations and exposure times. In the first test series, slides with grown cells were treated with 10 and $100 \mathrm{nM} \mathrm{DCT}$ concentration for $24 \mathrm{~h}$ (Batch 1) and $48 \mathrm{~h}$ (Batch 2), respectively. The cells of Batch 3 were incubated

Table 1 Overview of applied DCT treatments

\begin{tabular}{|c|c|c|c|}
\hline Batch & $\begin{array}{l}\text { Slide } \\
\text { number }\end{array}$ & $\begin{array}{l}\text { Exposure } \\
\text { time }(\mathrm{h})\end{array}$ & $\begin{array}{l}\text { DCT concentration } \\
(\mathrm{nmol} / \mathrm{l})\end{array}$ \\
\hline \multicolumn{4}{|c|}{ First test series } \\
\hline \multirow[t]{3}{*}{1} & T01 & 24 & 0 \\
\hline & T02 & & 10 \\
\hline & T03 & & 100 \\
\hline \multirow[t]{3}{*}{2} & T04 & 48 & 0 \\
\hline & T05 & & 10 \\
\hline & T06 & & 100 \\
\hline \multirow[t]{3}{*}{3} & T07 & $24+24$ & 0 \\
\hline & T08 & & 10 \\
\hline & T09 & & 100 \\
\hline \multicolumn{4}{|c|}{ Second test series } \\
\hline \multirow[t]{6}{*}{4} & $\mathrm{~T} 10$ & 48 & 0 \\
\hline & $\mathrm{T} 11$ & & 2.5 \\
\hline & $\mathrm{T} 11$ & & 5 \\
\hline & $\mathrm{T} 11$ & & 7.5 \\
\hline & $\mathrm{T} 12$ & & 10 \\
\hline & $\mathrm{T} 13$ & & 100 \\
\hline
\end{tabular}

for $24 \mathrm{~h}$ with DCT. Subsequently the DCT containing medium was replaced with a normal medium (without DCT). A cell cultivation step of further $24 \mathrm{~h}$ followed. The second test series (Batch 4) contained MCF-7 cells treated for $48 \mathrm{~h}$ with DCT concentrations of 2.5, 5 and $7.5 \mathrm{nmol} / 1$. Cultures of untreated cells were used as references. Each test series (batch) was prepared twice. For Raman data acquisition, the cells were air dried and stored at room temperature. For each batch, 2 to 6 cells were measured, while approximately 20,000 Raman spectra were recorded.

Hematoxylin and eosin staining

Hematoxylin and eosin (H\&E) staining was used as common histopathological analysis for comparison with the Raman data. H\&E staining allows the assignment of various structures in tissues and single cells [47]. Hematoxylin stains all basophilic components blue, especially the nucleus containing DNA and RNA, and the rough endoplasmatic reticulum with an accumulation of ribosomes as a result of a coordination bond between aluminum and phosphor atoms of the DNA and RNA [48]. Eosin stains the cytoplasm, connective tissue and collagen fibers (eosinophilic substances) red due to ionic bonds between the anionic dye and cationic plasma proteins. The samples were stained according to a well established standard protocol [49].

\section{Raman microspectroscopy}

Raman measurements were performed with the confocal Raman microscope [50] CRM 300 (WITec, Germany) equipped with a $50 \times /$ NA 0.95 objective (Zeiss, Germany). As excitation light, the $785 \mathrm{~nm}$ output of a diode laser was used with a power of $50 \mathrm{~mW}$ at the sample. For each spectrum, an acquisition time of $10 \mathrm{~s}$ was applied. The back scattered light was spectrally dispersed with a monochromator of $300 \mathrm{~nm}$ focus length equipped with a 600 lines/mm grating and detected by an EM-CCD camera with pixels operated at $-75^{\circ} \mathrm{C}$. The cell Raman maps were recorded with a step size of $0.5 \mu \mathrm{m}$.

\section{Chemometric evaluation}

The large amount of Raman data was evaluated applying chemometric methods. The calculations were performed on a commercially available PC system (Intel(R) Core(TM) 2Duo CPU, E67502.66 GHz, 1.97 GB RAM). The computations were done in $\mathrm{R}$ [51], a statistical language. All Raman spectra were preprocessed as described in a previous publication [32], while here only a brief overview is given.

First a wavenumber calibration employing the commonly used wavenumber standard 4-acetamidophenol was performed. For the chemometric analysis, the Raman spectra were truncated to the wavenumber region between 600 and $1,800 \mathrm{~cm}^{-1}$ (part of the fingerprint region). Afterwards, a background 
subtraction was performed applying a 5th order polynomial [52] to correct for the fluorescence background followed by a vector normalization. Prior to the analysis, a dimension reduction to 50 PCA scores was carried out to reduce the dimension of the data matrix without losing too much information. The chemometric analysis includes $k$-means cluster analysis [53], artificial neural networks (ANN) [32] and linear discriminant analysis (LDA) models [54]. While the $k$-means cluster analysis and the ANN were used for visualization, the LDA model was applied as a classification technique. The LDA was crossvalidated by a leave-one-out-cross-validation (LOO-CV) [55].

\section{Results and discussion}

Visualization of the cell morphology—qualitative analysis

DCT induces nucleus fragmentation due to apoptosis or mitotic catastrophe at the beginning of the effect chain $[9-11,16]$. For that reason, the first aim was the visualization of the morphology of MCF-7 cells. This will be an important step for further analyses, e.g. for the realization of a quantitative analysis presented in the "Determining the cell-drug response - quantitative analysis" section. In order to visualize the cell morphology, we applied an ANN to analyse the Raman $x y$-scans of whole single cells. The ANN analysis yields the DNA/RNA distribution for each measured Raman spectrum allowing the creation of a Raman image displaying the DNA/RNA content of the whole cell. These DNA/RNA Raman maps can be validated by comparing them with the histopathologic gold standard $\mathrm{H} \& \mathrm{E}$ staining. This validation of the applied ANN algorithm showed that DNA/RNA Raman maps display the position and shape of the cell nucleus.

Figure 1 compares the DNA/RNA distribution generated by an ANN with a subsequently stained H\&E image of the same non DCT treated cell. In the Raman image, high DNA/ RNA concentrations are displayed in red, while low concentrations appear blue. It can be clearly seen that the position, shape and size of the nucleus are comparable in both images. Furthermore, the lower left region of the cell (see encircled region in Fig. 1) shows one further structure both visible in the $\mathrm{H} \& \mathrm{E}$ as well as in the image generated by an ANN. The origin of this cannot be definitely clarified, but one possibility could be the presence of extra nuclear RNA, e.g. rough endoplasmatic reticulum or messenger, transfer or ribosomal RNA. This assumption was confirmed by Figure $\mathrm{S} 1$ in the Electronic Supplementary Material displaying Raman spectra from the nucleus and cytoplasm. The Raman spectra of cytoplasm and the nucleus show a significant Raman band at $811 \mathrm{~cm}^{-1}$ assigned to the vibration of the sugar-phosphate backbone of the RNA [56]. Therefore, the presence of extra nuclear RNA is probable in the nucleus as well as in the cytoplasm. Overall, Raman microspectroscopy provides similar information as the histological gold standard H\&E staining. The great advantage is that Raman microspectroscopy is label free and therefore potentially capable for in vivo applications in comparison with the H\&E stain. This proof-of-principle is necessary for further experiments dealing with the effect of docetaxel on living cancer cells over a longer period of time. To investigate such dynamic cellular events, a measurement technique requiring a label is not suitable. Raman microspectroscopy is label free and non-invasive and thus, cellular functions remain untouched in living cells during the measurement. Overall, the used ANN algorithm is ideally suited to identify Raman nuclei spectra, which can be further analysed (see the "Determining the cell-drug response - quantitative analysis" section).

In the following the ANN Raman images will be analysed with respect to identify structural differences in treated and untreated MCF-7 cells. Figure 2 (first row) depicts the Raman images of the DNA/RNA content of MCF-7 cells treated with 0,10 and $100 \mathrm{nmol} / 1 \mathrm{DCT}$ for $48 \mathrm{~h}$. In addition,
Fig. 1 Comparison of a MCF-7 cell stained with H\&E (left) and the chemical map of the DNA/ RNA distribution based on Raman spectroscopic data (right). The circle marks a structure in the cell with further DNA or RNA content outside the nucleus
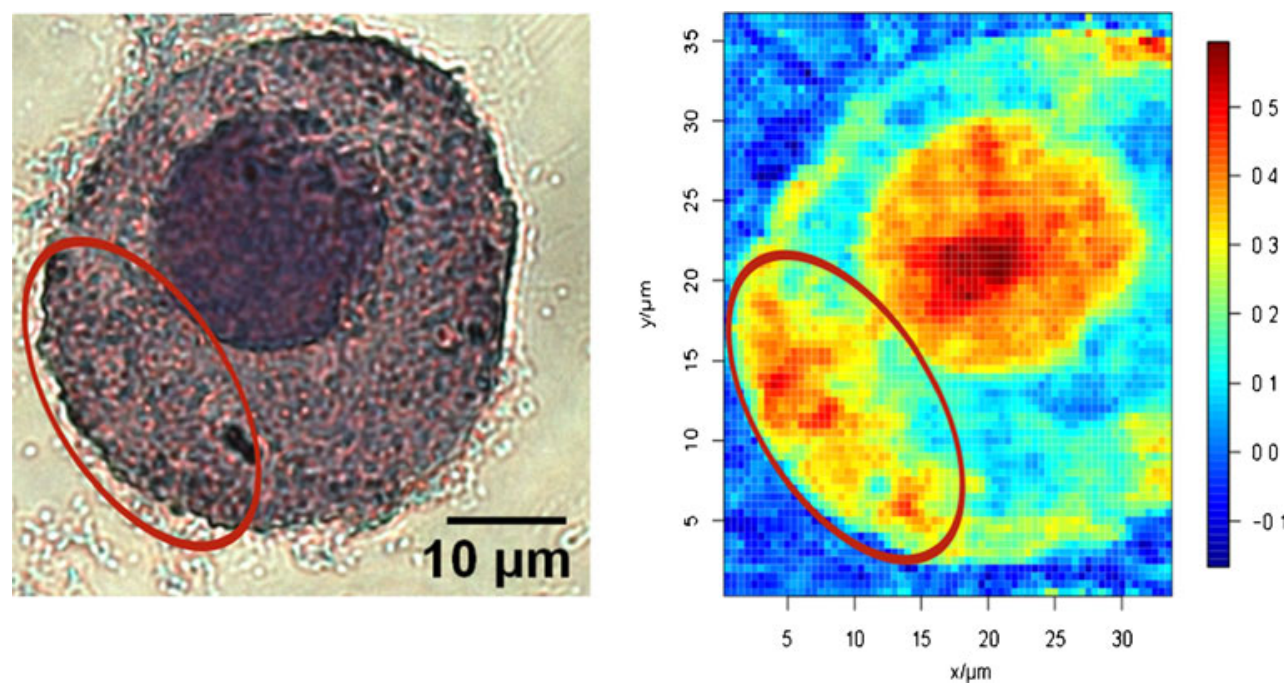

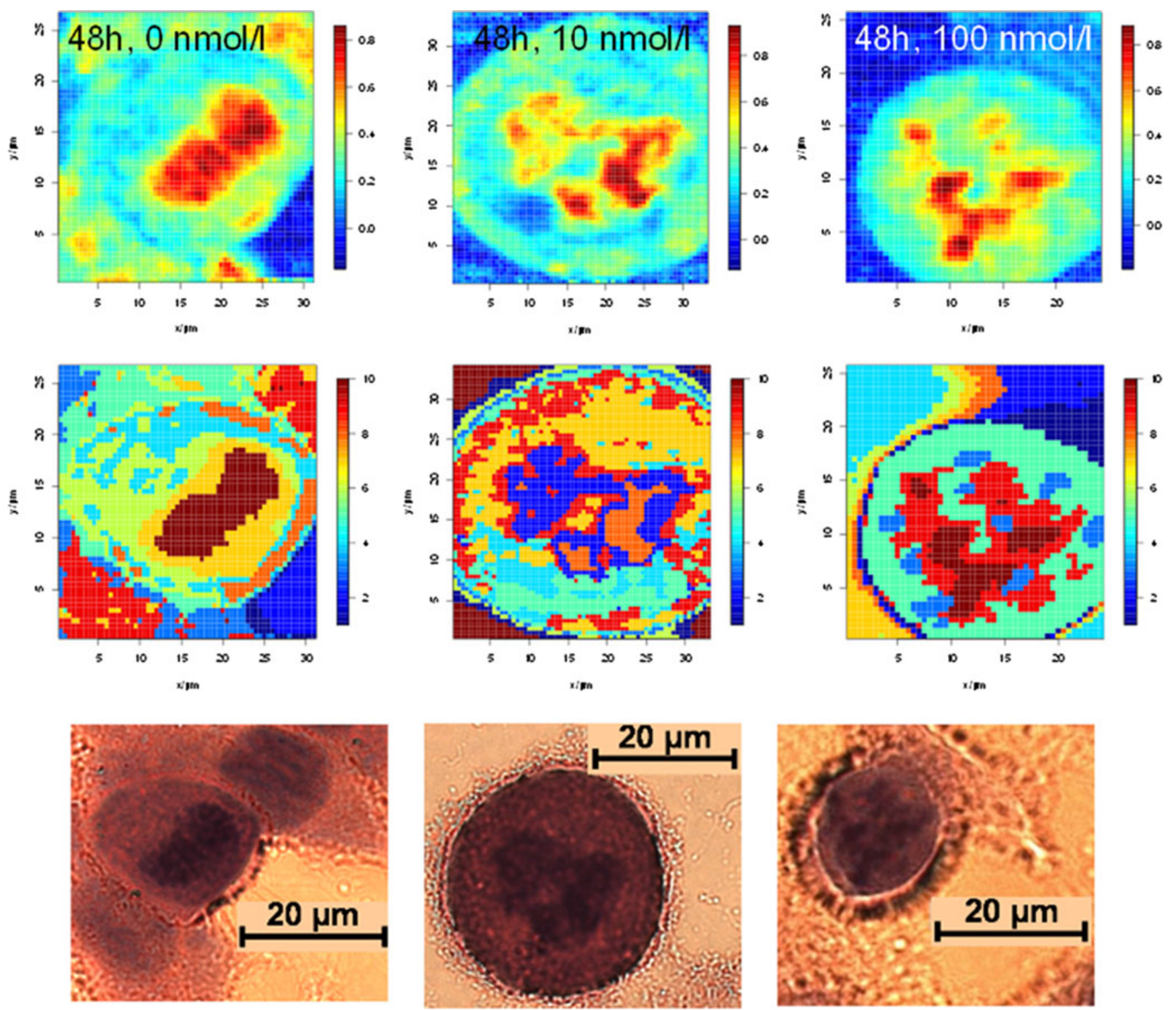

Fig. 2 Raman images of whole single cells generated by ANN analysis showing the DNA/RNA distribution of untreated $(0 \mathrm{nmol} / \mathrm{l})$ and DCT treated $(10 \mathrm{nmol} / \mathrm{l}, 48 \mathrm{~h}$ and $100 \mathrm{nmol} / \mathrm{l}, 48 \mathrm{~h}) \mathrm{MCF}-7$ cells. Dark red regions mark high DNA/RNA concentrations and thereby the nucleus position (1st row); results of the $k$-means cluster analysis ( 2 nd row) and corresponding H\&E images of the same cells (3rd row) $k$-means cluster analyses were carried out to visualize cell compartments, mainly the nucleus region (Fig. 2, second row). Both chemometrical methods (ANN and $k$-means cluster analysis) generated the same result: untreated (0 nmol/l) MCF-7 cells show compact cell nuclei, while the cells treated with $10 \mathrm{nmol} / \mathrm{l}$ as well as with $100 \mathrm{nmol} / \mathrm{l}$ DCT for $48 \mathrm{~h}$ exhibit fragmented nuclei. These pronounced differences between treated and untreated cells were confirmed by subsequent H\&E staining of the same samples (Fig. 2, third row).

Moreover, DCT induced effects on the cell morphology become visible in almost all measured MCF-7 cells. Some examples are shown in Figure S2 in the Electronic Supplementary Material. The Raman images illustrate once more an ANN calculation displaying the DNA/RNA content. These cells were treated with $100 \mathrm{nmol} / \mathrm{l} \mathrm{DCT}$ for the three different exposure times of $24 \mathrm{~h}, 48 \mathrm{~h}$ and $24+24 \mathrm{~h}$ (see Table 1). It can be clearly seen that almost all MCF-7 Raman images are characterized by fragmented nuclei. An exception from this behavior can be found for cell $2 \mathrm{C}$ showing a homogeneous cell nucleus, which might be attributed to the fact that DCT is only effecting cells during mitosis. Since the cell cycle was not synchronized, it is possible that the cell $2 \mathrm{C}$ was not in a mitotic stage. Furthermore, the individual behavior of a cell should be also considered.

However, these results point out that Raman microspectroscopy combined with chemometrical analysis has a great potential to image chemical changes in cells. The used ANN 
Table 2 Confidence table of the LDA model for separation of control data vs. Raman data containing cell-drug interactions

\begin{tabular}{lcc}
\hline Predicted labels & \multicolumn{2}{l}{ True labels } \\
\cline { 2 - 3 } & $\begin{array}{l}\text { Raman } \\
\text { spectra } \\
\text { of treated cells }\end{array}$ & $\begin{array}{l}\text { Raman spectra } \\
\text { of untreated } \\
\text { cells }\end{array}$ \\
\hline Raman spectra of treated cells & 10176 & 62 \\
Raman spectra of untreated cells & 77 & 8294 \\
\hline
\end{tabular}

algorithm is an optimal method to visualize the cell nuclei and thereby identify Raman nuclei spectra. The identification of nuclei spectra is an important step result for the subsequent quantitative analysis of the cell-drug response for DCT treated and untreated MCF-7 cells.

Determining the cell-drug response-quantitative analysis

It is of utmost importance to improve and personalize chemotherapy. Thereby the appropriate choice of the most effective chemotherapeutic drug for the individual patient and the possibility of an online monitoring of the progress of the chemotherapy are two of the major challenges towards increasing the effectiveness of cytostatic drugs and towards a personalized treatment. Raman microspectroscopy in combination with chemometrical methods has the potential to significantly contribute to tackle these challenges. Raman images in contrast to $\mathrm{H} \& \mathrm{E}$ images are of multivariate nature that is they contain additional spectral information which can be used to differentiate between untreated and treated MCF-7 cells or to unravel the (spectral) cell-drug response.

In order to differentiate between untreated and DCT treated MCF-7 cells, a LDA was utilized to classify the nucleus Raman spectra of treated and untreated cells. The resulting classification model was evaluated by a LOO-CV and the confusion matrix is given in Table 2. The LDA model classified 10,176 out of 10,253 cell nucleus Raman spectra of treated cells and 8,294 out of 8,356 cell nucleus Raman spectra from untreated cells correctly, which corresponds to an accuracy of $99.2 \%$. This accurcy rate together with the achieved sensitivity and specificity of also $99.2 \%$ shows that Raman microspectroscopy is perfectly suited to differentiate between treated and untreated MCF-7 cells. Figure 3 displays the mean Raman spectra of the two classes of the LDA model that is DCT treated (red) and untreated (black) MCF-7 cells together with the corresponding LD scaling vector. The LD scaling vector (green) indicates the spectral differences within the Raman spectra allowing for the clear separation between treated and untreated cells. A comparison between the mean Raman spectra of treated and untreated MCF-7 cells show that the intensity of the band at $785 \mathrm{~cm}^{-1}$ which can be assigned to a DNA/RNA vibration (OPO stretch DNA/RNA) $[56,57]$ is increased in the mean Raman spectrum of DCT treated cells as compared to untreated cells. The reason for this increasing $785 \mathrm{~cm}^{-1}$ band intensity could be a local DNA concentration enhancement due to the nucleus fragmentation and the corresponding
Fig. 3 Raman mean spectra of DCT treated (red spectrum) and untreated (black spectrum) MCF-7 cells. Significant differences are visible, e.g. the DNA/ RNA peak at $785 \mathrm{~cm}^{-1}$ and amide I peak at $1,658 \mathrm{~cm}^{-1}$. These regions are confirmed by the LD scaling vector (green spectrum)

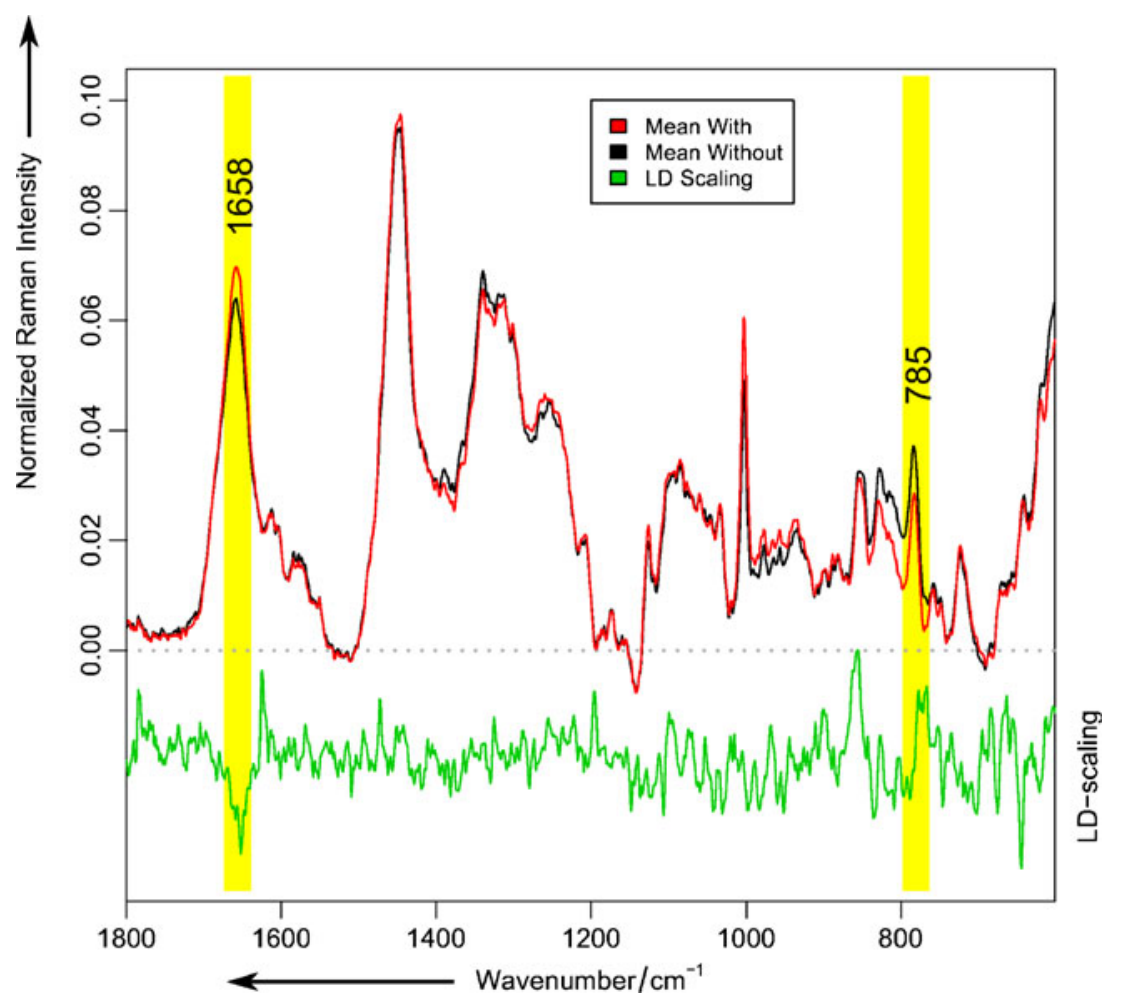


increased DNA condensation. Furthermore the amide I vibration at $1,658 \mathrm{~cm}^{-1}[56,57]$ is decreased in intensity in the mean Raman spectrum of treated MCF-7 cells as compared to the spectrum of untreated cells, which might be also a consequence of the nucleus fragmentation and the corresponding degradation of the protein structures in the nucleus.

In order to investigate DCT concentration dependent cellresponse Raman spectra recorded for cells treated with 2.5, 5, $7.5,10$, and $100 \mathrm{nmol} / \mathrm{l} \mathrm{DCT}$ for $48 \mathrm{~h}$ were analysed (see Table 1). It should be noted that only the Raman spectra originating from the cell nucleus were considered. A LDA model was used to calculate the spectral differences between the five different concentrations. The LDA model was trained with two training sets including Raman spectra of cells exposed to DCT concentrations of 2.5 and $100 \mathrm{nmol} / 1$ for $48 \mathrm{~h}$ to achieve the corresponding LD scaling vector. As test sets, Raman spectra of cells treated with 5, 7.5, and $10 \mathrm{nmol} /$ 1 DCT were projected on this LD scaling vector. Figure 4A gives an overview of the drug concentration dependent class affinities. Here, the distribution of the scalar product of each Raman spectrum with the calculated LD vector is shown (LD value). Overall, the LDA analysis reveals that the highest cell response occurs after a treatment with DCT concentrations between 7.5 and $10 \mathrm{nmol} / \mathrm{l}$ showing that the lowest concentration that is detection limit where the influence of DCT on the MCF-7 Raman spectra is still visible lies at a DCT concentration of $7.5 \mathrm{nmol} / \mathrm{l}$. In Fig. 4B, the $\mathrm{LD}$ value (e.g. the inner product of every spectrum with the LDA value) is plotted against the drug concentration on a logarithmic scale. This LD value can be interpreted as the cell response. The points in Fig. 4B result from the maxima of the histogram in Fig. 4A for every DCT concentration. The arrangement of the values suggests a sigmoidal trend, which confirms studies about the dose-effect relationship by Jodrell et al. [58] and Jakobsen et al. [59]. These findings indicate, that even low DCT concentrations of $7.5 \mathrm{nmol} / 1$ induce chemical alterations in MCF-7 cells.

\section{A}
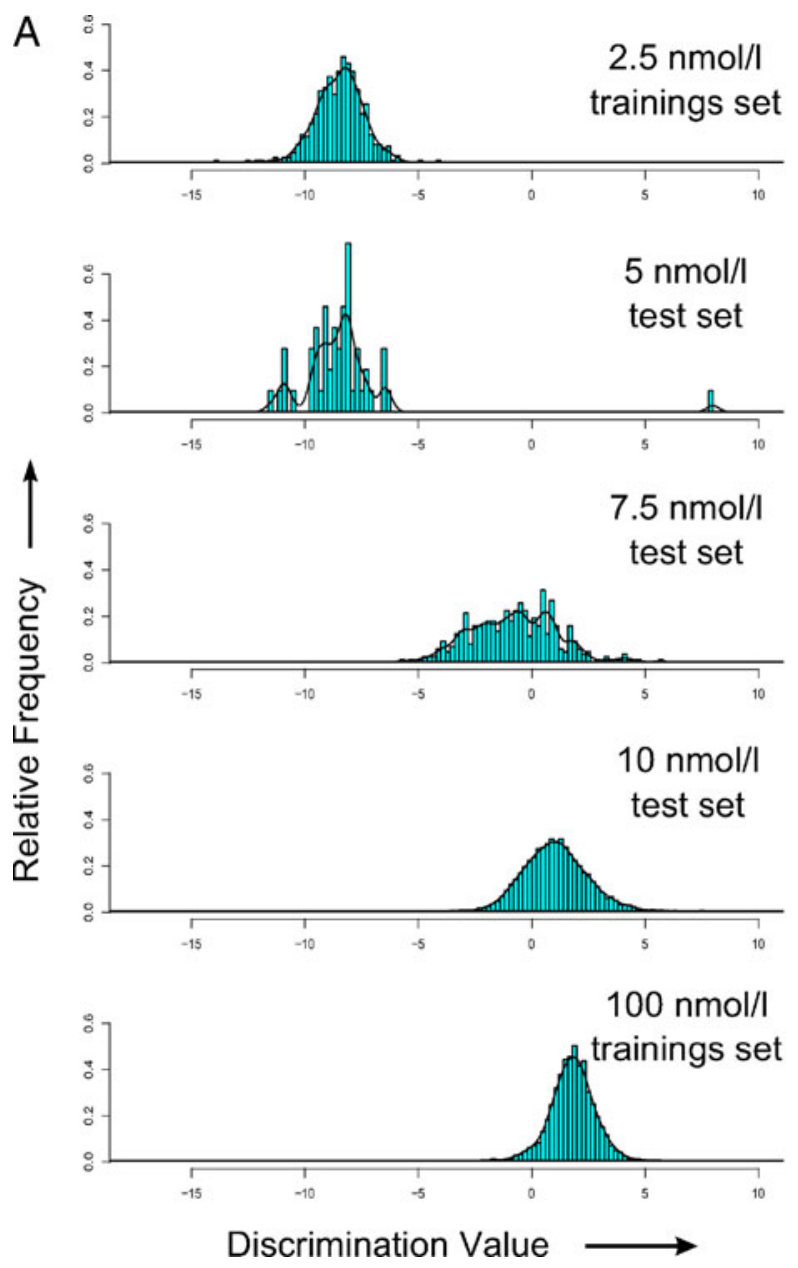

Fig. 4 (A) LDA classification of Raman data of various DCT treatments. The histogram of the LD value (scalar product) of all five DCT concentrations is given. With the lowest and highest concentration, the LDA model was trained and all spectra were projected on the LDA model. (B)

\section{B}

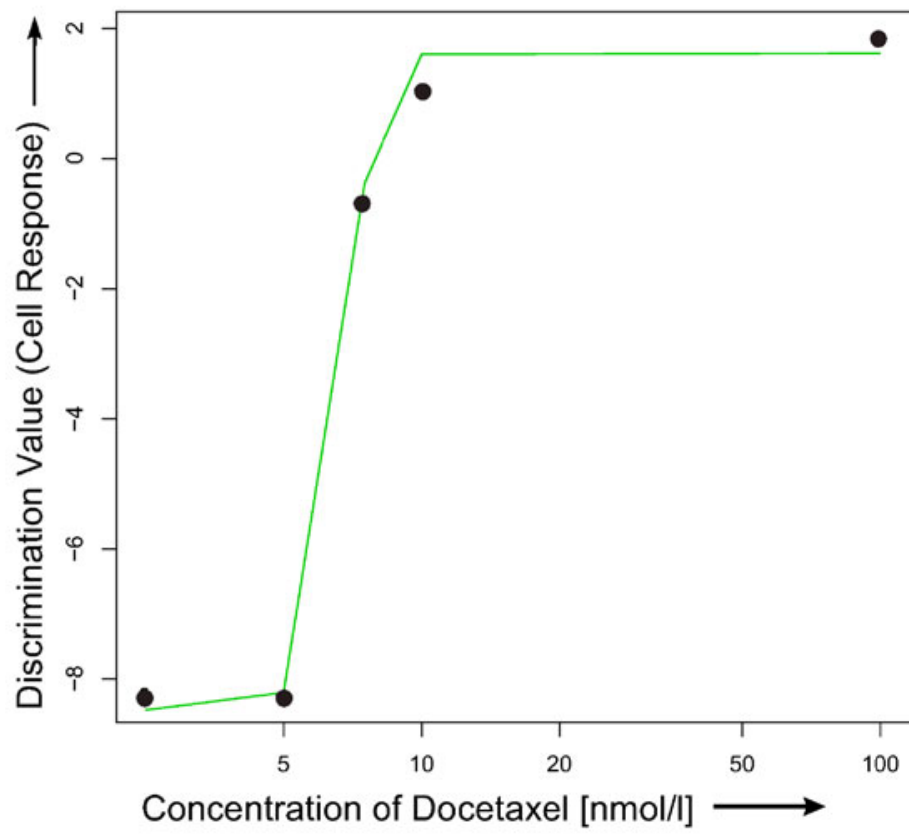

The dose-effect relationship, as a function of the logarithmically DCT concentration, is visualized. The LD-value can be interpreted as cell response for DCT treatment and shows a sigmoidal trend, which can be utilized for determining the spectral detection limit 


\section{Conclusion}

We investigated DCT induced effects on a breast cancer model system (MCF-7) by means of Raman microspectroscopy in combination with powerful chemometrical methods. DCT induces nucleus fragmentation at the beginning of the effect chain. Therefore, we visualized the morphology of cell organelles, e.g. the cell nucleus by applying $k$-means cluster analysis and an ANN. The ANN generated images are highly correlating with the DNA/RNA content. The in that way generated Raman images highlighted DCT induced morphological alterations in the nuclei structure, caused by the drug induced depolymerisation of microtubules during mitosis. These images based on Raman spectra were validated with the histopathologic gold standard method, the H\&E staining. Overall, both Raman imaging analysing methods ( $k$-means clustering and ANN) were capable of visualization the cell morphology.

By using a LDA with the preselected nuclei spectra, it was possible to differentiate between treated and untreated MCF-7 cells with an accuracy of $99.2 \%$. Thereby, Raman mean spectra of DCT treated and untreated cells show significant differences at $785 \mathrm{~cm}^{-1}$, which can be assigned to a DNA/RNA vibration, and the amide I peak at $1,658 \mathrm{~cm}^{-1}$ due to the DCT induced fragmentation of the nuclei. DCT treatments with concentrations lower than $10 \mathrm{nmol} / \mathrm{l}(2.5,5$ and $7.5 \mathrm{nmol} / \mathrm{l})$ were implemented additionally to achieve quantitative results about the efficiency of DCT by applying a LDA analysis. A drug concentration of $7.5 \mathrm{nM}$ was indicated as the detection limit of monitoring spectral changes in Raman spectra of treated MCF-7 cells.

In the present contribution, it was shown that the analysis of cellular Raman spectra by means of modern chemometric approaches is capable of monitoring the impact of cytostatic agents. The effect of a drug on the cell morphology can be visualized and the spectral differences between treated and untreated cells can be calculated. With the help of the visualization and detection of the effect of chemotherapeutic drugs it could be possible to monitor the ongoing chemotherapy. This could be achieved by applying the presented methodology on real patient cell samples. In that way, the process and the benefit of an ongoing chemotherapy would be determined in an objective manner. Therefore an individualized medicine with Raman spectroscopy as control tool seems reasonable. The above presented results can be used in another way. If quantum mechanical calculations (based on DFT calculations or in the Hartree-Fock regime) $[60,61]$ of DCT, microtubules and the respective motor proteins are carried out, a deeper understanding of the work mechanism of DCT can be obtained. This workflow is outlined in [62, 63]. Nevertheless, the quantum mechanical calculations have to be optimized for the application to huge proteins and cell structures. This is an emerging field, which in combination with experimental data, like presented above, would enhance our understanding of the bio-chemical processes inside of cells and the their interaction with drugs.

Acknowledgements The authors gratefully thank Ms. Cornelia Jörke from the Department of Hematology and Oncology in Jena for the preparation of the cell samples and Michael Schmitt from the Institute of Physical Chemistry, University of Jena, for useful comments and suggestions for improving the manuscript. The funding of the research project "Exprimage" (FKZ 13N9364) within the framework "Biophotonik" and "Markerfreie Zelldiagnostik mit Nanometerauflösung" (0312032B) from the Federal Ministry of Education and Research, Germany (BMBF) is gratefully acknowledged.

Open Access This article is distributed under the terms of the Creative Commons Attribution License which permits any use, distribution, and reproduction in any medium, provided the original author(s) and the source are credited.

\section{References}

1. Ferlay J, Shin H, Bray F, Forman D, Mathers C, Parkin D (2008) GLOBOCAN 2008, cancer incidence and mortality worldwide: IARC cancerbase no. $10 \mathrm{http}: / /$ globocan.iarc.fr

2. Spear BB, Heath-Chiozzi M, Huff J (2001) Trends Mol Med 7:201-204

3. Sargent J, Taylor C (1989) Br J Cancer 60:206-210

4. Nagourney RA (2006) Curr Treat Options Oncol 7:103-110

5. Mollgard L, Tidefelt U, Sundman-Engberg B, Lofgren C, Paul C (2000) Leuk Res 24:445-452

6. Miller ML, Ojima I (2001) Chem Rec 1:195-211

7. Radaideh SM, Sledge GW (2008) Breast Cancer Res Treat 111:203-208

8. Bissery MC, Guenard D, Gueritte-Voegelein F, Lavelle F (1991) Cancer Res 51:4845-4852

9. Morse DL, Gray H, Payne CM, Gillies RJ (2005) Mol Cancer Ther 10:1495-1504

10. Hernández-Vargas H, Palacios J, Moreno-Bueno G (2007) Cell Cycle 6:780-783

11. Creane M, Seymour CB, Colucci S, Mothersill C (1999) Int J Radiat Biol 75:731-737

12. Blajeski AL, Kottke TJ, Kaufmann SH (2001) Exp Cell Res 270:277-288

13. Jordan MA, Wendell K, Gardiner S, Derry WB, Copp H, Wilson L (1996) Cancer Res 56:816-825

14. Demarcq C, Bunch RT, Creswell D, Eastman A (1994) Cell Growth Differ 5:983-993

15. Waldman T, Lengauer C, Kinzler KW, Vogelstein B (1996) Nature 381:713-716

16. Hernández-Vargas H, Palacios J, Moreno-Bueno G (2007) Oncogene 26:2902-2913

17. Rösch P, Harz M, Schmitt M, Popp J (2005) J Raman Spectrosc $36: 377-379$

18. Neugebauer U, Bocklitz T, Clement JH, Krafft C, Popp J (2010) Analyst 135:3178-3182

19. Harz M, Kiehntopf M, Stoeckel S, Roesch P, Deufel T, Popp J (2008) Analyst (Cambridge, UK) 133:1416-1423

20. Notingher I, Verrier S, Haque S, Polak JM, Hench LL (2003) Biopolymers 72:230-240

21. Krishna CM, Sockalingum GD, Kegelaer G, Rubin S, Kartha VB, Manfait M (2005) Vib Spectrosc 38:95-100

22. Krause M, Rösch P, Radt B, Popp J (2008) Anal Chem 80:85688575 
23. Schmid U, Rösch P, Krause M, Harz M, Popp J, Baumann K (2009) Chemom Intell Lab Syst 96:159-171

24. Krause M, Radt B, Rösch P, Popp J (2007) J Raman Spectrosc 38:369-372

25. Gaus K, Rösch P, Petry R, Peschke KD, Ronneberger O, Burkhardt H, Baumann K, Popp J (2006) Biopolymers 82:286-290

26. Harz M, Kiehntopf M, Stöckel S, Rösch P, Straube E, Deufel T, Popp J (2009) J Biophoton 2:70-80

27. Hermelink A, Brauer A, Lasch P, Naumann D (2009) Analyst (Cambridge, U K) 134:1149-1153

28. Maquelin K, Kirschner C, Choo-Smith LP, van den Braak N, Endtz HP, Naumann D, Puppels GJ (2002) J Microbiol Methods 51:255-271

29. Cialla D, Deckert-Gaudig T, Budich C, Laue M, Möller R, Naumann D, Deckert V, Popp J (2009) J Raman Spectrosc 40:240-243

30. Krafft C, Dietzek B, Popp J (2009) Analyst 134:1046-1057

31. Vogler N, Meyer T, Akimov D, Latka I, Krafft C, Bendsoe N, Svanberg K, Dietzek B, Popp J (2010) J Biophoton 3:728-736

32. Bocklitz T, Putsche M, Stüber C, Käs J, Niendorf A, Rösch P, Popp J (2009) J Raman Spectrosc 40:1759-1765

33. Kneipp J, Bakker Schut T, Kliffen M, Menke-Pluijmers M, Puppels G (2003) Vib Spectrosc 32:67-74

34. Harz M, Kiehntopf M, Stöckel S, Rösch P, Deufel T, Popp J (2007) Analyst 133:1416-1423

35. Notingher I, Jell G, Lohbauer U, Salih V, Hench LL (2004) J Cell Biochem 92:1180-1192

36. Taleb A, Diamond J, McGarvey JJ, Beattie JR, Toland C, Hamilton PW (2006) J Phys Chem B 110:19625-19631

37. Hedegaard M, Matthäus C, Hassing S, Krafft C, Diem M, Popp J (2011) Theor Chem Acc 130:1249-1260

38. Lasch P, Boese M, Pacifico A, Diem M (2002) Vib Spectrosc 28:147-157

39. Buckmaster R, Asphahani F, Thein M, Xub J, Zhang M (2009) Analyst 134:1440-1446

40. Zoladek A, Pascut FC, Patel P, Notingher I (2011) J Raman Spectrosc 42:251-258

41. Okada M, Smith NI, Palonpon AF, Endo H, Kawata S, Sodeoka M, Fujita K (2012) Proc Natl Acad Sci USA 109:28-32

42. Manfait M, Alix AJP, Jeannesson P, Jardillier JC, Theophanides T (1982) Nucleic Acids Res 10:3803-3816

43. Moritz TJ, Taylor DS, Krol DM, Fritch J, Chan JW (2010) Biomed Opt Express 1:1138-1147
44. Yan Q, Priebe W, Chaires JB, Czernuszewicz RS (1997) Biospectroscopy 3:307-316

45. El-Said WA, Kim TH, Kim H, Choi JW (2011) Biosens Bioelectron 26:1486-1492

46. Soule HD, Vazquez J, Long A, Albert S, Brennan M (1973) J Natl Cancer Inst 51:1409-1416

47. Humphreys TR, Nemeth A, McCrevey S, Baer SC, Goldberg LH (1996) Dermatol Surg 22:693-697

48. Lüllmann-Rauch R (2006) Taschenlehrbuch Histologie Georg Thieme Verlag, Stuttgart

49. Sigma-Aldrich (2003) Mayers Hämatoxylin-Lösung Verfahrens Nr. MHS AR-MED Ltd.

50. Baia L, Gigant K, Posset U, Petry R, Schottner G, Kiefer W, Popp J (2002) Vib Spectrosc 29:245-249

51. R Development Core Team (2007) R: a language and environment for statistical computing $\mathrm{R}$ foundation for statistical computing Vienna, Austria

52. Lieber CA, Mahadevan-Jansen A (2003) Appl Spectrosc 57:13631367

53. Ding C, He X (2004) In: Proceedings of the 21st International Conference on Machine Learning

54. Fisher RA (1936) Annals Eugen 7:179-188

55. Kohavi R (1995) In: Proceedings of the International Joint Conference on Artificial Intelligence Morgan Kaufmann 11371143

56. Notingher I, Hench LL (2006) Expert Rev Med Devices 3:215234

57. Krafft C, Knetschke T, Siegner A, Funk RHW, Salzer R (2003) Vib Spectrosc 32:75-83

58. Jodrell DI, Egorin MJ, Canetta RM, Langenberg P, Goldbloom EP, Burroughs JN, Goodlow JL, Tan S, Wiltshaw E (1992) J Clin Oncol 10:520-528

59. Jakobsen A, Mortensen LS (1997) Acta Oncol 36:375-381

60. Frauenheim T, Seifert G, Elstner M, Niehaus T, Köhler C, Amkreutz M, Sternberg M, Hajnal Z, Carlo A, Suhai S (2002) J Phys Condens Matter 14:3015

61. Han W, Jalkanen K, Elstner M, Suhai S (1998) J Phys Chem B 102:2587-2602

62. March N, Matthai C (2010) Theor Chem Acc 125:193-201

63. Piva J, Silva J, Raniero L, Martin A, Bohr H, Jalkanen K (2011) Theor Chem Acc 130:1261-1273 